\begin{tabular}{|c|c|}
\hline 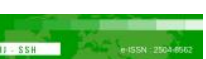 & Malaysian Journal of Social Sciences and Humanities (MJSSH) \\
\hline Malaysian Journal of & Volume 6, Issue 3, March 2021 \\
\hline (MJ-SSH) & e-ISSN : 2504-8562 \\
\hline & $\begin{array}{l}\text { Journal home page: } \\
\text { www.msocialsciences.com }\end{array}$ \\
\hline
\end{tabular}

\title{
Daya Tahan, Strategi Daya Tindak Serta Hubungannya Terhadap Tahap Kesejahteraan Psikologi Guru
}

\author{
Nadia Abd. Razak ${ }^{1}$,Faridah Mydin Kutty ${ }^{1}$ \\ ${ }^{1}$ Fakulti Pendidikan, Universiti Kebangsaan Malaysia (UKM) \\ Correspondence: Nadia Abd. Razak (p95809@siswa.ukm.edu.my)
}

\begin{abstract}
Abstrak
Kajian ini bertujuan untuk mengkaji tahap daya tahan guru, strategi daya tindak, tahap kesejahteraan psikologi dan melihat hubungan antara tahap daya tahan dan strategi daya tindak terhadap tahap kesejahteraan psikologi guru-guru di Kuala Pilah. Kajian ini menggunakan pendekatan kuantitatif berasaskan reka bentuk tinjauan. Populasi kajian terdiri daripada guru-guru sekolah rendah di daerah Kuala Pilah. Kaedah persampelan rawak mudah digunakan dan seramai 258 orang guru telah terlibat sebagai sampel kajian. Instrumen kajian mengadaptasi soal selidik daripada The Resilience Scale, Brief COPE dan Fluorishing Scale (FS). Data dianalisis secara deskriptif menggunakan kekerapan, min dan sisihan piawai manakala secara inferensi menggunakan Korelasi Pearson. Dapatan kajian menunjukkan guru-guru di Kuala Pilah mempunyai tahap daya tahan yang tinggi $(\mathrm{M}=5.68, \mathrm{SP}=0.626)$, lebih cenderung menggunakan strategi daya tindak berfokuskan masalah apabila berhadapan dengan sumber stres $(\mathrm{M}=2.99, \mathrm{SP}=0.353)$, dan mempunyai tahap kesejahteraan psikologi yang tinggi $(\mathrm{M}=6.13, \mathrm{SP}=0.574)$. Selain itu, dapatan menunjukkan terdapatnya hubungan yang signifikan di antara tahap daya tahan dengan tahap kesejahteraan psikologi guru-guru $(\mathrm{r}=0.640, \mathrm{p}<0.01)$ dan strategi daya tindak guru $(\mathrm{r}=0.254, \mathrm{p}<0.01)$. Pihak KPM dapat memanfaatkan dapatan ini untuk menyediakan latihan-latihan mapan yang mendedahkan guru-guru mengenai kesedaran terhadap kesejahteraan psikologi dan kepentingan pemilihan strategi daya tindak yang betul apabila berhadapan dengan sumber stres.
\end{abstract}

Kata kunci: tahap daya tahan, strategi daya tindak, tahap kesejahteraan psikologi

\section{Resilence and Coping Strategies: Its Relationship to Teachers' Psychological Well- Being}

\begin{abstract}
This study was undertaken to investigate the level of resilience among teachers, coping strategies, level of psychological well-being and its relationship towards the level of psychological well-being of teachers in Kuala Pilah. This study used quantitative approach based on a cross-sectional survey design and data was collected using questionaires. The study population consists of primary school teachers in Kuala Pilah. A total of 258 teachers were selected using simple random sampling. The research instruments adapted the questionnaire from The Resilience Scale by Wagnild \& Young (1990) to observe the level of resilience, Brief COPE Questionnaires (Carver, 1997) to observe the coping strategies and the questionnaire from the Fluorishing Scale (FS) by Diener et. al (2009) to observe the level of psychological well-being. The data were analysed using descriptive and inferential method. The findings showed that teachers in Kuala Pilah have high level of resilience $(\mathrm{M}=5.68, \mathrm{SD}=0.626)$, more
\end{abstract}


likely to use problem-focused coping strategies when dealing with stress sources ( $\mathrm{M}=2.99, \mathrm{SD}=0.353)$, and have high level of psychological well-being $(\mathrm{M}=6.13, \mathrm{SD}=0.574)$. Pearson Correlation findings indicated that there is a significantly positive relationship between the level of resilience and the coping mechanisms towards the level of psychological among teachers $(r=0.254, p<0.01)$. The results of this study can be used by MOE to provide trainings that could exposes teachers towards the awareness of psychological well-being and the importance of choosing the right coping strategies when dealing with stress sources.

Keywords: resilience level, coping strategies, level of psychological well-being

\section{Pengenalan}

Guru merupakan agen transformasi yang terlibat secara langsung dalam melaksanakan dasar Kementerian Pendidikan Malaysia untuk meningkatkan kualiti pendidikan dan kemenjadian anak bangsa. Seiring dengan era semasa, mutu pendidikan di Malaysia turut memerlukan anjakan transformasi agar dapat bersaing sejajar dengan globalisasi pendidikan seluruh dunia. Pelan Pembangunan Pendidikan Malaysia (PPPM) 2013-2025 menekankan peningkatan standard pembelajaran dan keluwesan operasi bagi membangunkan kecemerlangan profesional. Oleh yang demikian, guru-guru seharusnya mempunyai daya tahan dan mempunyai strategi daya tindak yang baik bagi memastikan guru-guru berkhidmat dalam keadaan tahap kesejahteraan psikologi yang baik.

Kesejahteraan psikologi merupakan indikator penting yang menyumbang kepada produktiviti kerja, tahap kesihatan mental dan fizikal seseorang (Angie, 2019). Kesejahteraan psikologi merujuk kepada keupayaan individu untuk menerima diri dan orang lain di persekitarannya, sentiasa positif dengan mengisi hidupnya dengan perkara-perkara yang bermakna buat dirinya dan orang lain serta mengetahui akan potensi diri serta mengembangkan potensi yang ada (Khoirani, 2018). Kajian-kajian yang dijalankan menunjukkan terdapatnya hubungan yang signifikan antara aspek tahap kesejahteraan psikologi guru terhadap kepuasan kerja guru, hubungan dengan rakan sekerja dan juga pencapaian murid. Selain itu, guru yang mempunyai tahap kesejahteraan psikologi yang baik mempunyai motivasi serta harga diri, semangat bekerja yang tinggi di samping lebih prihatin terhadap pencapaian akademik muridmuridnya (Sarah, 2018). Berdasarkan dapatan-dapatan kajian lepas, tahap kesejahteraan psikologi secara tidak langsung menyumbang kepada kepuasan kerja guru.

Oleh yang demikian, kesedaran tentang daya tahan dan pemilihan strategi daya tindak akan dapat membantu guru-guru untuk melalui liku dan cabaran sebagai pendidik dengan lebih berkesan (Triana, 2019). Definisi daya tahan menurut Wagnild dan Young (1993) ialah kemampuan individu untuk mengadaptasi diri dengan kesusahan yang dialami dalam hidupnya, tidak kira lah sama ada kesusahan tersebut dialami secara berterusan atau sementara. Strategi daya tindak menurut Lazarus (1993) pula ialah usaha yang diambil oleh individu untuk mengurangkan tekanan yang dihadapi dengan mengubah keadaan emosi atau menyingkirkan sumber-sumber yang menjadi punca tekanan.

Justeru, kajian yang dijalankan berfokus kepada bagaimana daya tahan dan strategi daya tindak mempengaruhi tahap kesejahteraan psikologi guru. Kajian ini diharap dapat membantu guru dalam menghadapi cabaran dalam kehidupan harian khususnya di sekolah. Kajian-kajian lepas lebih banyak melihat dari aspek intervensi dan faktor-faktor yang mempengaruhi kesejahteraan psikologi seperti tahap kepuasan bekerja, dan efikasi kendiri guru. Namun, kajian yang dilakukan untuk melihat bagaimana kualiti dalaman seperti aspek daya tahan dan strategi daya tindak mempengaruhi kesejahteraan psikologi guru masih belum begitu meluas terutamanya dalam konteks sekolah rendah di luar bandar. Oleh itu, objektif dalam kajian ini ialah untuk mengkaji hubungan antara daya tahan dan daya tindak terhadap tahap kesejahteraan psikologi dalam guru-guru sekolah rendah di daerah Kuala Pilah.

Penulisan seterusnya akan dibahagikan kepada beberapa subtopik yang membincangkan tentang definisi, konsep dan sorotan literatur berkaitan daya tahan, strategi daya tindak dan kesejahteraan 
psikologi guru-guru. Subtopik seterusnya pula membincangkan tentang metodologi yang digunakan dalam memperoleh data dan membincangkan dapatan kajian. Subtopik terakhir membincangkan tentang kesimpulan serta implikasi yang diperoleh dari kajian ini.

\section{Sorotan Literatur}

\section{Definisi Kesejahteraan Psikologi, Daya Tahan dan Strategi Daya Tindak}

Kesejahteraan psikologi menurut Ryff (1989) merupakan keupayaan individu untuk menjalin perhubungan positif dengan masyarakat sekelilingnya, mempunyai makna dan objektif hidup, berkemampuan menangani konflik, mempunyai daya tahan, serta berkemampuan mengembangkan citacita dan potensi diri. Dalam konteks kajian ini, guru yang mempunyai kesejahteraan psikologi akan berasa gembira dan positif dengan hidupnya, mempunyai interaksi sosial yang baik dengan masyarakat lingkungannya, serta mempunyai konsep kendiri yang baik. Selain itu, guru-guru yang mempunyai tahap kesejahteraan psikologi pada tahap yang baik juga mempunyai tahap efikasi dan kepuasan kerja yang baik (Çimen \& Özgan, 2018).

Daya tahan menurut Wagnild dan Young (1993) ialah kemampuan individu untuk mengadaptasi diri dengan kesusahan yang dialami dalam hidupnya. Menurut Benders dan Jackson (2012) pula, daya tahan bermaksud percaya pada diri sendiri akan kebolehan menempuh sesuatu cabaran dengan penuh cekap dan berkesan. Oleh yang demikian, dalam konteks kajian ini konsep daya tahan merujuk kepada kemampuan guru untuk bertahan dan beradaptasi dengan kesusahan yang dialami dan berkebolehan untuk bouncing back iaitu kembali stabil dari segi emosi dan fizikal setelah melalui sesuatu kesukaran dan pengalaman lepas tersebut menjadikan guru tersebut mempunyai daya tahan yang lebih kuat. Di samping itu, guru yang mempunyai daya tahan yang baik juga dapat menerima kehidupan dan orang lain di sekitarnya dengan baik serta berusaha meningkatkan usaha untuk memberi komitmen terhadap organisasi dan tugas hakikinya (Mansfield et al., 2016).

Lazarus dan Folkman (1984) berpendapat, strategi daya tindak ialah gabungan kognitif dan tingkah laku seseorang untuk menyelesaikan masalah dan tekanan yang dihadapi. Izazol (2019) pula mendefinisikan daya tindak sebagai usaha-usaha untuk menyelesaikan sesuatu masalah dengan menggunakan pemikiran dan tingkah laku yang bersesuaian. Dalam konteks kajian ini, daya tindak merujuk kepada gabungan penggunaan kognitif dan tingkah laku serta bagaimana guru-guru memilih langkah terbaik sebagai solusi kepada permasalahan yang dihadapinya. Keberkesanan guru-guru dalam memilih mekanisme daya tindak yang betul bukan sahaja membantu meningkatkan profesionalisme dan komitmen terhadap tugasnya, malah meningkatkan tahap kesejahteraan psikologi dan kesihatan fizikalnya (Betoret, 2006).

\section{Teori dan Model}

Model Daya Tahan Wagnild (1993), Teori Penilaian Kognitif Lazarus (1984) dan Model Kesejahteraan Subjektif Diener (1984) merupakan model dan teori yang mendasari kajian ini. Pengkaji memilih modelmodel dan teori tersebut kerana bersesuaian dengan tujuan dan objektif kajian iaitu melihat tahap daya tahan, strategi daya tindak serta hubungannya dengan kesejahteraan psikologi dalam konteks profesion keguruan.

Model Daya Tahan Wagnild dan Young (1993) menyatakan bahawa daya tahan merupakan satu elemen penting dalam diri individu untuk bangkit kembali setelah melalui kesusahan dalam hidupnya dan aspek daya tahan ini terdiri daripada lima dimensi iaitu Kepercayaan Atas Diri, Ketenangan, Kesungguhan, Kehidupan Bermakna dan Falsafah Kesunyian. Dalam konteks kajian ini, kesungguhan dan rasa percaya pada diri sendiri membantu guru melaksanakan amanah dalam aspek pembelajaran dan pemudahcaraan membolehkan seseorang guru berupaya mengekalkan komitmennya walaupun diuji dengan rintangan atau tekanan yang berulang-ulang (Salmi, 2016). 
Teori Penilaian Kognitif (Cognitive Appraisal Theory) diasaskan oleh Lazarus dan Folkman (1984). Teori ini menyatakan bahawa proses penilaian kognitif merupakan proses yang berlaku sepanjang hidup manusia dan melibatkan proses menilai tentang sebab dan mengapa sesuatu perkara boleh menjadi sumber stres terhadap diri seseorang serta terdiri daripada dimensi daya tindak berfokuskan masalah dan daya tindak berfokuskan emosi (Lazarus \& Folkman, 1984). Berdasarkan kepada model daya tindak, sumber-sumber stres dan cabaran yang sering dihadapi oleh guru dapat dikaitkan dengan hubungan manusia dan persekitaran seperti kekurangan masa rehat, keperluan menyelesaikan tugasan berkaitan dokumentasi, kepadatan pelajar yang tinggi di dalam kelas, kekurangan sumber untuk mengakses dan mendapatkan alat bantu mengajar dan juga berdepan dengan masalah tingkah laku pelajar (Hose, 2020).

Teori Kesejahteraan Subjektif Diener menyatakan bahawa kesejahteraan psikologi dicapai bergantung kepada seberapa banyak peristiwa positif dan negatif dikumpulkan dalam hidup seseorang (Diener et al, 1999). Proses ini melibatkan persepsi, keyakinan dan personaliti seseorang yang membantunya menilai sesuatu situasi yang dialami ke arah menuju kesejahteraan hidupnya sendiri (Ariati, 2017). Angie (2019) menyatakan bahawa guru mempunyai tahap kesejahteraan psikologi yang baik apabila guru tersebut berjaya menghadapi dan mengatasi cabaran dalam profesionnya menggunakan kemahirannya dari aspek psikologi, sosial dan fizikal.

\section{Tahap Daya Tahan Dan Strategi Daya TindakSebagaiPeramal Tahap Kesejahteraan Psikologi}

Dalam pada itu, kajian-kajian lepas juga mengaitkan tahap kesejahteraan psikologi guru dengan tahap daya tahan dan daya tindak guru. Antaranya ialah kajian oleh Ienats (2017) terhadap guru di Indonesia mendapati pemilihan daya tindak yang betul ketika menghadapi tekanan dapat meningkatkan tahap kesejahteraan psikologi guru. Antaranya ialah kajian oleh Ainsworth dan Oldfield (2019) di United Kingdom yang menyatakan guru yang mempunyai daya tahan dan tahap kepuasan kerja yang baik mempunyai tahap kesejahteraan psikologi yang baik. Walau bagaimanapun, kajian yang melihat bagaimana aspek daya tahan dan strategi daya tindak mempengaruhi tahap kesejahteraan psikologi dalam konteks profesion keguruan di Malaysia terutamanya di sekolah rendah luar bandar masih belum begitu meluas. Oleh yang demikian penyelidik berpendapat menjalankan kajian untuk melihat hubungan daya tahan dan strategi daya tindak terhadap tahap kesejahteraan psikologi guru-guru merupakan satu keperluan. Kewajaran kajian ini juga adalah berdasarkan kepada keperluan kepada pihak Kementerian Pendidikan Malaysia untuk membantu guru-guru berkhidmat dengan lebih cemerlang, mencapai kepuasan kerja dan menunjukkan prestasi yang optimum di samping dapat beradaptasi dengan cabaran dan transformasi dalam pendidikan.

\section{Metod Kajian}

Kajian ini menggunakan pendekatan kuantitatif yang menggunakan reka bentuk tinjauan dan seramai 258 orang dipilih secara persampelan rawak mudah sebagai sampel kajian daripada keseluruhan populasi guru-guru sekolah rendah di daerah Kuala Pilah. Instrumen kajian pula mengadaptasi soal selidik daripada The Resilience Scale oleh Wagnild dan Young (1990), soal selidik Brief COPE (Carver, 1997) dan Fluorishing Scale (FS) oleh Diener et. al (2009). Kesahan pakar telah dijalankan ke atas ketiga-tiga soal selidik. Soal selidik terdiri daripada 4 bahagian. Bahagian A demografi, bahagian B tahap daya tahan guru, bahagian $\mathrm{C}$ berkaitan strategi daya tindak guru dan bahagian D berkaitan tahap psikologi guru. Analisis deskriptif melibatkan nilai kekerapan, peratus, min dan sisihan piawai manakala analisis inferensi menggunakan Ujian Korelasi Pearson. Hasil ujian rintis mencatatkan nilai kebolehpercayaan alpha Cronbach, $\alpha$ bagi Instrumen Tahap Daya Tahan adalah 0.931 manakala Strategi Daya ialah 0.868 dan Tahap Kesejahteraan Psikologi pula ialah 0.902. 


\section{Hasil Kajian}

\section{Analisis Jantina Dan Pengalaman Mengajar Guru}

Jadual 1 menunjukkan profil responden berdasarkan jantina. Seramai 115 orang atau 44.6 peratus terdiri daripada guru lelaki, manakala seramai 143 orang atau 55.4 peratus lagi terdiri daripada guru perempuan. Seterusnya, dalam jadual 2 dipaparkan profil responden mengikut pengalaman mengajar. Seramai 26 orang $(10.1 \%)$ adalah terdiri daripada guru berpengalaman antara 0 hingga 5 tahun, 48 orang (18.6\%) daripada guru berpengalaman antara 6 hingga 10 tahun dan 184 orang $(71.3 \%)$ lagi daripada guru berpengalaman 11 tahun ke atas. Ini menunjukkan bahawa kebanyakan responden yang terlibat dalam kajian ini adalah dari kalangan guru berpengalaman 11 tahun ke atas.

Jadual 1: Jadual Taburan Jantina Responden

\begin{tabular}{llcc}
\hline Demografi & Sub-profil & Bilangan & Peratus \\
\hline Jantina & Lelaki & 115 & 44.6 \\
& Perempuan & 143 & 55.4 \\
\hline
\end{tabular}

Jadual 2: Jadual Taburan Pengalaman Mengajar Responden

\begin{tabular}{llcc}
\hline Ciri & Sub-profil & Bilangan & Peratus \\
\hline Pengalaman mengajar & 0 hingga 5 tahun & 26 & 101 \\
& 6 hingga 10 tahun & 48 & 18.6 \\
& 11 tahun ke atas & 184 & 71.3 \\
\hline
\end{tabular}

\section{Tahap Daya Tahan Guru}

Jadual 3 menunjukkan bahawa skor dimensi daya tahan guru yang paling tinggi ialah falsafah kesunyian $(\min =5.84)$, diikuti oleh kesungguhan $(\min =5.69)$, makna kehidupan $(\min =5.68)$, ketenangan $(\min$ $=5.62)$ dan dimensi kepercayaan atas diri $(\min =5.54)$. Secara keseluruhannya, data menunjukkan skor tahap daya tahan $(\min =5.68)$ dalam kalangan guru di daerah Kuala Pilah, Negeri Sembilan adalah berada pada tahap yang tinggi.

Jadual 3: Min dan Sisihan Piawai Tahap Daya Tahan Guru

\begin{tabular}{llll}
\hline & Min & SP & Tahap \\
\hline Kepercayaan atas diri & 5.54 & .802 & Tinggi \\
Makna kehidupan & 5.68 & .749 & Tinggi \\
Ketenangan & 5.62 & .750 & Tinggi \\
Kesungguhan & 5.69 & .647 & Tinggi \\
Falsafah kesunyian & 5.84 & .819 & Tinggi \\
\hline Keseluruhan (Tahap daya tahan & $\mathbf{5 . 6 8}$ & $\mathbf{. 6 2 6}$ & Tinggi \\
guru) & & &
\end{tabular}

\section{Strategi Daya Tindak Guru}

Secara keseluruhannya, Jadual 4 di bawah menunjukkan skor dimensi daya tindak guru iaitu daya tindak berfokuskan emosi $(\min =2.91)$ dan daya tindak berfokuskan masalah $(\min =2.99)$. Oleh yang demikian, dapat dirumuskan bahawa daya tindak berfokuskan masalah merupakan strategi yang tertinggi digunakan oleh guru-guru Kuala Pilah. 
Jadual 4: Min dan Sisihan Piawai Strategi Daya Tindak Guru

\begin{tabular}{ccc}
\hline & Min & SP \\
\hline Daya tindak berfokuskan emosi & 2.91 & .363 \\
Daya tindak berfokuskan masalah & 2.99 & .353 \\
\hline Keseluruhan & $\mathbf{2 . 9 5}$ & $\mathbf{. 3 3 2}$ \\
\hline (Strategi daya tindak guru) & & \\
\hline
\end{tabular}

\section{Tahap Kesejahteraan Psikologi Guru}

Dalam kajian ini, tahap kesejahteraan psikologi guru diukur oleh 8 item. Secara keseluruhannya menunjukkan bahawa skor tahap kesejahteraan psikologi $(\min =6.13$, SP $=0.574)$ dalam kalangan guruguru di Kuala Pilah, Negeri Sembilan adalah berada pada tahap yang tinggi.

Jadual 5 Min dan Sisihan Piawai Tahap Kesejahteraan Psikologi Guru

\begin{tabular}{ccc}
\hline & Min & SP \\
\hline Tahap Kesejahteraan Psikologi & 6.13 & .574 \\
\hline Tahap Keseluruhan & & Tinggi \\
\hline
\end{tabular}

\section{Hubungan Antara Daya Tahan Dan Daya Tindak Dengan Kesejahteraan Psikologi Guru}

Jadual 6: Hubungan antara Daya Tahan dan Daya Tindak dengan Kesejahteraan Psikologi Guru

\begin{tabular}{lcc}
\hline & \multicolumn{2}{c}{ Kesejahteraan psikologi guru } \\
\cline { 2 - 3 } & $\mathbf{r}$ & Sig. $\mathbf{P}$ \\
\hline Daya tahan guru & $0.640^{* *}$ & .000 \\
Daya tindak guru & $0.254^{* *}$ & .000 \\
\hline$* * \mathrm{p}<0.01$ & &
\end{tabular}

Kekuatan hubungan antara pemboleh ubah diinterpretasi berdasarkan nilai pekali, $r$ berpandukan tafsiran pekali korelasi oleh Cohen (1998) sebagaimana di dalam Jadual 8.

Jadual 7: Jadual interpretasi pekali korelasi

\begin{tabular}{lc}
\hline \multicolumn{1}{c}{ Pekali korelasi,r } & Kekuatan hubungan \\
\hline 0.10 hingga 0.29 & lemah \\
0.30 hingga 0.49 & sederhana \\
0.5 hingga 1.0 & kuat \\
\hline
\end{tabular}

Sumber: Cohen (1988)

Jadual 6 di atas menunjukkan keputusan pengujian hipotesis kesan langsung menghasilkan dua dapatan penting. Pertama, daya tahan guru $(r=0.640, p<0.01)$ mempunyai hubungan yang signifikan dengan kesejahteraan psikologi guru-guru di Kuala Pilah. Dengan itu, Ho1 adalah gagal diterima. Kedua, daya tindak guru $(r=0.254, p<0.01)$ mempunyai hubungan yang signifikan dengan kesejahteraan psikologi guru-guru di Kuala Pilah. Dengan itu, Ho2 adalah gagal diterima. 


\section{Perbincangan Kajian}

Kajian ini bertujuan mengkaji tahap daya tahan dan strategi daya tindak yang digunakan oleh guru-guru ketika berhadapan dengan sumber stres serta melihat hubungan daya tahan dan strategi daya tindak terhadap tahap kesejahteraan psikologi guru-guru. Hasil dapatan kajian mendapati guru-guru di Kuala Pilah mempunyai tahap daya tahan yang tinggi dan guru-guru didapati lebih menggunakan strategi daya tindak berfokuskan masalah berbanding daya tindak berfokuskan emosi ketika berhadapan dengan sumber stres serta mempunyai tahap kesejahteraan psikologi yang tinggi. Selain itu, dapatan kajian juga menunjukkan terdapatnya hubungan yang signifikan antara tahap daya tahan dan strategi daya tindak terhadap tahap kesejahteraan psikologi guru-guru.

Tahap daya tahan yang tinggi menunjukkan guru-guru di Kuala pilah mempunyai kebolehan untuk beradaptasi atau pun bouncing back yang baik selepas melalui sesuatu kesukaran dalam hidupnya di samping mengetahui kekuatan serta limitasi diri dan berupaya mencari alternatif serta maksud di sebalik sesuatu kejadian yang berlaku dalam hidupnya. Dalam konteks kajian ini, aspek kepercayaan atas diri mencatatkan nilai min yang tinggi menunjukkan guru-guru di Kuala Pilah mempunyai kompetensi diri yang tinggi. Hal ini kerana guru-guru di daerah Kuala Pilah sentiasa menerima bimbingan secara langsung oleh pegawai-pegawai Pejabat Pendidikan Daerah (PPD) dalam menambah baik kompetensi dan tugasan sekaligus meningkatkan kompetensi dan tahap daya tahan guru-guru di daerah ini. Menurut Brunetti (2006), rasa percaya pada diri sendiri membantu guru mengekalkan komitmennya terhadap tugas hakikinya walaupun diuji dengan rintangan atau tekanan yang berulang-ulang.

Selain itu, guru-guru di Kuala Pilah juga lebih cenderung memilih strategi daya tindak berfokuskan masalah kerana dilihat dapat membantu untuk mengubah, menghapuskan dan menyelesaikan masalah dari sumber stres secara langsung manakala daya tindak berfokuskan emosi digunakan untuk mengurangkan dan meminimumkan stres dari sumber stres dengan menghindari sumber stres tersebut (Jonathan, 2019).

Secara keseluruhan, dapat disimpulkan bahawa guru yang mempunyai tahap daya tahan yang baik mempunyai tahap kesejahteraan psikologi yang baik kerana berkemampuan untuk mengadaptasi diri dengan kesusahan yang dialami dalam hidupnya, dan guru yang menggunakan strategi daya tindak dengan baik mempunyai tahap kesejahteraan psikologi yang baik kerana berupaya menyelesaikan sesuatu masalah dengan menggunakan pemikiran dan tingkah laku yang bersesuaian dengan sumber stres. Hasil dapatan disokong oleh kajian oleh Brouskeli et al. (2018) yang mendapati terdapatnya korelasi yang positif antara daya tahan dan tahap kesejahteraan psikologi guru-guru.

\section{Kesimpulan}

Kesimpulannya, kajian ini membuktikan tahap daya guru dan strategi daya tindak guru mempunyai hubungan yang signifikan dengan tahap kesejahteraan psikologi guru-guru. Oleh itu pengkaji mencadangkan agar guru-guru mengamalkan keseimbangan kerja dan hidup dengan baik di samping menguasai kemahiran komunikasi secara berkesan untuk membina hubungan positif untuk mengekalkan kesihatan fizikal dan mental. Di samping itu, pihak Kementerian Pendidikan Malaysia dicadangkan agar menyediakan latihan dalam perkhidmatan yang bersesuaian untuk mendedahkan kepada guru-guru mengenai kesedaran terhadap kesejahteraan psikologi, kepentingan pemilihan strategi daya tindak yang betul apabila berhadapan dengan sumber stres dan pengurusan stres yang betul. Seterusnya, sebagai cadangan kajian lanjutan, pengkaji seterusnya juga boleh meluaskan kajian ini kepada skop sekolah yang lebih luas seperti sekolah-sekolah swasta dan sekolah-sekolah yang telah diiktiraf sebagai Sekolah Berprestasi Tinggi (SBT) dan menggunakan pemboleh ubah seperti Spiritual Quotient (SQ) dan kecerdasan menghadapi cabaran (AQ) untuk menghubungkaitkan kajian ini. 


\section{Rujukan}

Ah, S. H. A. B., \& Omar, N. (2020). Pementoran Dalam Program Pembangunan Guru Baharu Kementerian Pendidikan Malaysia. The Malaysian Journal of Social Administration, 14(2), 79-95.

Ainsworth, S., \& Oldfield, J. (2019). Quantifying teacher resilience: Context matters. Teaching and Teacher Education, 82, 117-128.

Akram, M. (2019). Psychological Wellbeing of University Teachers in Pakistan. Journal of Education and Educational Development, 6(2), 235-253.

Amin, N. B., Amir, A. M., \& Ismail, S. F. (2019). Key Performance Indicators Tugas, Ganjaran Dan Prestasi Kerja Guru Sekolah Kerajaan. JuPiDi: Jurnal Kepimpinan Pendidikan, 6(4), 38-60.

Ariati, J. (2017). Subjective Well-Being (Kesejahteraan Subjektive) Dan Kepuasan Kerja Pada Staf Pengajar (Dosen) Di Lingkungan Fakultas Psikologi Universitas Diponegoro. Jurnal Psikologi Undip.

Benders, D. S., \& Jackson, F. A. (2012). Teacher resiliency: Nature or nurture. International Journal of Humanities and Social Science, 2(16), 103-110.

Brunetti, G. J. (2006). Resilience under fire: Perspectives on the work of experienced, inner city high school teachers in the United States. Teaching and teacher education, 22(7), 812-825.

Cancio, E. J., Larsen, R., Mathur, S. R., Estes, M. B., Johns, B., \& Chang, M. (2018). Special education teacher stress: Coping strategies. Education and Treatment of Children, 41(4), 457-481

Cohen, J. (1988). Statistical power analysis for the behavioural sciences. Hillsdale, NJ: Laurence Erlbaum Associates.

Creswell, J.D. (2005)..International Edition. Educational Research. Planning, Conducting and Evalating Quantitative and Qualitative Research Second Edition. New Jersey: Pearson Education International.

Creswell, J. W., \& Creswell, J. D. (2017). Research design: Qualitative, quantitative, and mixed methods approaches. Sage publications.

Diener, E., \& Ryan, K. (2009). Subjective well-being: A general overview. South African journal of psychology, 39(4), 391-406.

Diener, E., Suh, E. M., Lucas, R. E., \& Smith, H. L. (1999). Subjective well-being: Three decades of progress. Psychological bulletin, 125(2), 276.

Fajriani, I. T., \& Suprihatin, T. (2018). Harga Diri, Kepuasan Kerja Dan Kesejahteraan Subjektif Pada Guru Madrasah Tsanawiyah. Proyeksi: Jurnal Psikologi, 12(1), 67-76.

Idris, I. (2019). Pengaruh Resiliensi, Daya Tindak, Dan Kecerdasan Menghadapi Cabaran Terhadap Kesejahteraan Psikologi Dalam Kalangan Pelajar Universiti (Doctoral dissertation, Universiti Sains Malaysia).

Indrawati, T. (2019). Pengaruh Resiliensi dan Religiusitas Terhadap Kesejahteraan Psikologis Pada Guru di PAUD Rawan Bencana ROB. Al-Athfaal: Jurnal Ilmiah Pendidikan Anak Usia Dini, 2(2), 71-82.

Karahan, T. F., Yalcin, B. M., Erbas, M. M., \& Ergun, S. (2019). The relationship between the dominant humor style, emotional intelligence, and problem-solving skills in trainee teachers in Turkey. Humor, 32(1), 73-95.

Kasapoglu, K., \& Didin, M. (2019). Life Skills as a Predictor of Psychological Well-Being of PreService Pre-School Teachers in Turkey. International Journal of Contemporary Educational Research, 6(1), 70-85.

Kementerian Pendidikan Malaysia. (2013). Pelan pembangunan pendidikan Malaysia 2013-2025. Putrajaya: Kementerian Pendidikan Malaysia.

Kementerian Pendidikan Malaysia. (2016). Laporan tahunan 2015.Pelan PembangunanPendidikan Malaysia (PPPM) 2013-2025. Putrajaya: Kementerian Pendidikan Malaysia.

Komolafe, M. (2019). The Resiliency of Veteran Preschool Special Education Teachers (Doctoral dissertation, Brandman University).

Lazarus, R. S. (1993b). From psychological stress to the emotions: A history of changing outlooks. Annual review of psychology, 44(1), 1-22.

Lazarus, R. S., \& Folkman, S. (1984). Stress, appraisal, and coping. Springer publishing company.

Leow, K., Lee, C. C. E., \& Leow, S. W. Y. (2020). Job satisfaction and mental wellbeing among high school teachers in Malaysia. Jurnal Psikologi Malaysia= The Malaysian Journal of Psychology, 34(3), 128-139. 
Liao, Y. H., Luo, S. Y., Tsai, M. H., \& Chen, H. C. (2020). An exploration of the relationships between elementary school teachers' humor styles and their emotional labor. Teaching and Teacher Education, 87, 102950.

Morettini, B., Luet, K., \& Vernon-Dotson, L. (2020). Building Beginning Teacher Resilience: Exploring the Relationship between Mentoring and Contextual Acceptance. In The Educational Forum, 84, 1, 48-62. Routledge.

Osman, M. S. (2016). Hubungan Antara Dimensi Kecerdasan Emosi, Spritual Dan Fizikal Dengan Daya Tahan Dalam Kalangan Guru Sekolah Menengah. Universiti Putra Malaysia.

Pogere, E. F., López-Sangil, M. C., García-Señorán, M. M., \& González, A. (2019). Teachers' job stressors and coping strategies: Their structural relationships with emotional exhaustion and autonomy support. Teaching and Teacher Education, 85, 269-280.

Razmjoo, S. A., \& Ayoobiyan, H. (2019). On the relationship between teacher resilience and selfefficacy: The case of Iranian EFL teachers. Journal of English Language Teaching and Learning, 11(23), 277-292.

Ryff, C. D. (1989). Beyond Ponce de Leon and life satisfaction: New directions in quest of successful ageing. International journal of behavioral development, 12(1), 35-55.

Wagnild, G. M., \& Young, H. M. (1993). Development and psychometric. Journal of nursing measurement, 1(2), 165-17847.

Wigford, A., \& Higgins, A. (2019). Wellbeing in international schools: Teachers' perceptions. Educational \& Child Psychology, 36(4), 46-64.

Wong, J. P., Tome, C. M., \& Wong, A. M. (2019). Demographic Group Differences in Stress Coping Mechanism: The Case of Public-School Administrators in the Division of Romblon. 